\title{
Repartição de nutrientes nos ramos, folhas e flores do cafeeiro ${ }^{(1)}$
}

\author{
Eurípedes Malavolta(2), José Laércio Favarin ${ }^{(3)}$, Marcelo Malavolta( ${ }^{(3)}$, Cleusa Pereira Cabral(3), \\ Reges Heinrichs ${ }^{(3)}$ e José Sebastião Machado Silveira(3)
}

\begin{abstract}
Resumo - Estudou-se a repartição de nutrientes nos ramos, folhas e flores na antese da primeira fase reprodutiva do cafeeiro (Coffea arabica L.), cultivares Mundo Novo IAC 388-17 enxertada sobre Apoatã IAC 2258 (4.000 plantas ha-1) e Catuaí Amarelo IAC 62 (5.000 plantas ha $\left.{ }^{-1}\right)$. No florescimento, coletou-se um ramo plagiotrópico no terço médio de 20 plantas, contando, em média, 37 e 29 ramos floríferos na cultivar Mundo Novo e Catuaí Amarelo, respectivamente, separando-se flores, folhas, e ramo (lenho). As flores do cafeeiro constituem um forte dreno de nutrientes, variável entre as cultivares; o acúmulo de nutrientes pelas cultivares Catuaí Amarelo e Mundo Novo antecede a antese no início da primavera, e a extração total de $\mathrm{Mg}$ pelas flores das cultivares representa 52\% do extraído pelas partes da planta (flores, folhas e ramos), o que sugere que a adubação do cafeeiro deve iniciar antes do florescimento.
\end{abstract}

Termos para indexação: Coffea arabica, floração, nutrientes minerais, disponibilidade de nutrientes.

\section{Nutrients repartition in the coffee branches, leaves and flowers}

\begin{abstract}
The nutrients repartition in the coffee (Coffea arabica L.) branches, leaves and flowers were studied at anthesis of the first reproductive phase for Mundo Novo IAC 388-17 cultivar grafted on Apoatã IAC 2258 (4,000 plants ha-1) and Catuaí Amarelo IAC 62 (5,000 plants ha') cultivars. At flowering, the reproductive branches were collected using its median third part computing 37 and 29 flowering branches of Mundo Novo and Catuaí Amarelo cultivars, respectively, where the flowers, leaves and branches were separated. The coffee flowers are an important physiological drain of nutrients, changeable among cultivars; the nutrients accumulation by Mundo Novo and Catuaí Amarelo cultivars was verified before the anthesis, at the beginning of Spring season, and the total $\mathrm{Mg}$ extraction by flowers represents $52 \%$ of the flowers, leaves and branches extraction, indicating that the coffee fertilization must initiate before flowering phase.
\end{abstract}

Index terms: Coffee Arabica, flowering, mineral nutrients, nutrient availability.

\section{Introdução}

A exigência nutricional das cultivares Mundo Novo e Catuaí é crescente a partir dos primeiros 6 meses até 78 meses de idade após o plantio (6,5 anos), apresentando comportamento semelhante à acumulação de matéria seca, independentemente da quantidade de fruto produzida (Corrêa et al., 1986).

\footnotetext{
(1) Aceito para publicação em 25 de setembro de 2001 .

(2) Universidade de São Paulo (USP), Centro de Energia Nuclear na Agricultura (Cena), Caixa Postal 96, CEP 13400-970 Piracicaba, SP. E-mail:mala@cena.usp.br (3) USP-Escola Superior de Agricultura Luiz de Queiroz (Esalq), Dep. de Produção Vegetal, Caixa Postal 9, CEP 13418-900 Piracicaba, SP. E-mail: jlfavari@carpa.ciagri.usp.br
}

A demanda de nutrientes pelo cafeeiro não varia em virtude da produção, pois quando a frutificação é baixa, o crescimento de ramos plagiotrópicos, a formação de folhas e ramos novos substituem o fruto como dreno de carboidratos e nutrientes.

De acordo com Melotto (1987), a principal fonte de carboidratos para os botões florais é a fotossíntese e não as reservas contidas nas folhas e ramos, o que, segundo Rena et al. (1996), sugere elevado grau de dependência do estado nutricional da planta e da relação funcional entre folha e fruto. A dependência do cafeeiro desta relação funcional deve-se à característica da espécie de não regular a carga de frutos, que em grande quantidade em relação a área foliar provoca distúrbios fisiológicos como a seca de ponteiros (die back).

O número de flores viáveis depende de vários fatores, entre os quais a temperatura (Mes, 1957), a 
disponibilidade de água (Portères, 1946; Huxley \& Ismail, 1969) e estado nutricional. As exigências minerais das flores e depois dos frutos devem ser satisfeitas pelo solo, pelo adubo e pela mobilização de reservas dos órgãos de residência, como ramos, folhas e raízes.

Em condições naturais, após a quebra de dormência dos botões florais e a antese, transcorre aproximadamente 7 a 15 dias (Frederico \& Maestri, 1970). Neste curto período, os elementos condutores do pedicelo floral são formados intensamente, ampliando o lúmen dos vasos (Moens, 1968; Astegiano, 1984), acompanhando o incremento superior a seis vezes da taxa de produção de matéria fresca e até 25 vezes de matéria seca dos órgãos florais (Barros et al., 1978), caracterizando uma fase de intensa mobilização de água e fotoassimilados.

Como o botão floral e as flores desenvolvem-se com as primeiras chuvas na primavera, esta fase fisiologicamente ativa do cafeeiro depende da atividade da planta no inverno. Neste período, quando o padrão de crescimento da parte aérea é pequeno (Barros \& Maestri, 1974; Amaral, 1991), as raízes continuam funcionais fisiologicamente (Amaral, 1991), em virtude do maior saldo de carboidratos, pois, o crescimento da parte aérea é menor, sem haver paralisação do processo fotossintético (Rena, 2000). Durante o inverno, as raízes acumulam compostos nitrogenados como aminoácidos e reguladores de crescimento e transporta-os para a parte aérea, contribuindo para o crescimento no início da primavera (Amaral, 1991; Matta et al., 1999).

A maioria dos trabalhos realizados sobre nutrição mineral de café aborda prioritariamente a quantidade de nutrientes alocados nas folhas, ramos plagiotrópicos, frutos e raízes, não havendo estudos com enfoque para as flores, em relação a quantidade de nutrientes acumulados neste órgão, assim como nas folhas e ramos no florescimento.

O objetivo deste trabalho foi estudar a repartição de nutrientes nos ramos, folhas e flores em duas cultivares de café.

\section{Material e Métodos}

Os materiais foram colhidos na área experimental do Departamento de Produção Vegetal da Esalq, Universida- de de São Paulo, e da Fazenda Nova Java, no Município de Piracicaba, SP. Foram utilizadas as cultivares Mundo Novo IAC 388-17 enxertada sobre Apoatã IAC 2258, com 40 meses de idade, e Catuaí Amarelo IAC 62, com 30 meses de idade.

As determinações de matéria fresca e matéria seca, e as análises químicas para a determinação de macronutrientes e micronutrientes foram realizadas no Laboratório de Nutrição Mineral de Plantas do Centro de Energia Nuclear na Agricultura-Cena/USP.

Os cafeeiros foram plantados nos espaçamentos de 2,5 m x 1,0 m ('Mundo Novo') e 2,0 m x 1,0 m ('Catuaí Amarelo'), formando uma população de 4.000 plantas ha-1 e 5.000 plantas ha $^{-1}$, em solos pertencentes à mesma classe Terra Roxa Latossólica e Terra Roxa Estruturada, respectivamente.

As avaliações foram realizadas em cafeeiros que se encontravam na primeira fase reprodutiva do ciclo de crescimento e desenvolvimento, com folhas distribuídas em toda extensão dos ramos plagiotrópicos, exceto na cultivar Mundo Novo, que apresentava alguma desfolha causada pela infestação do bicho-mineiro, Leucoptera coffeella (Guérin-Mèneville).

No primeiro dia após a antese coletaram-se, aleatoriamente, durante o período da manhã, um ramo plagiotrópico localizado no terço médio de 20 plantas, totalizando 20 ramos floríferos de cada cultivar. Durante a coleta, realizou-se a contagem dos ramos plagiotrópicos com flores nas plantas amostradas, desde a base até a parte superior do cafeeiro, com a finalidade de obter-se o número médio de ramos floríferos, tendo sido contabilizados 37 ramos na 'Mundo Novo' e 29 ramos na 'Catuaí Amarelo'. Esse procedimento teve a finalidade de estimar a quantidade total de nutrientes e da matéria seca de cada parte da planta, possibilitando a extrapolação dos resultados obtidos para 1 ha de café.

Os ramos coletados foram reunidos, ao acaso, em quatro grupos de cinco ramos plagiotrópicos, constituindo as repetições, dos quais separaram-se as flores, folhas e ramos. Após homogeneização determinou-se a matéria fresca, e depois da secagem durante 72 horas em estufa a $70^{\circ} \mathrm{C}$, a matéria seca dos ramos, folhas e flores, os quais foram analisados separadamente em relação a macronutrientes e micronutrientes, conforme Malavolta et al. (1997).

A estimativa da quantidade de nutrientes $\left(\mathrm{Q}_{\mathrm{N}}\right)$ contidas nas flores e folhas de cada ramo por planta de café, bem como no próprio ramo do cafeeiro, foi determinada conforme a expressão 1 :

$\mathrm{Q}_{\mathrm{N}}=$ (teor do órgão $\mathrm{x}$ matéria seca do órgão $\mathrm{x} \mathrm{n}$ o de ramos planta $\left.^{-1}\right) / 1.000$,

sendo o fator 1.000 aplicado para a obtenção dos resulta- 
dos de macronutrientes em $\mathrm{g}$ planta ${ }^{-1}$ e micronutrientes em mg planta $^{-1}$. A extrapolação para $1 \mathrm{ha}\left(\mathrm{Q}_{\mathrm{ha}}\right)$ foi feita considerando-se a densidade de plantio das respectivas cultivares, conforme a expressão 2:

$\mathrm{Q}_{\mathrm{ha}}=\left(\mathrm{Q}_{\mathrm{N}} \times \text { plantas ha-1 }\right)^{-1} / .000$,

aplicando-se o fator 1.000 para a obtenção dos resultados de macronutrientes em $\mathrm{kg} \mathrm{ha}^{-1} \mathrm{e}$ micronutrientes em $\mathrm{g} \mathrm{ha}^{-1}$.

\section{Resultados e Discussão}

Não se verificou diferença estatística em relação às variáveis matéria fresca e matéria seca de ramos plagiotrópicos, evidenciando que a amostragem foi adequada (Tabela 1). A menor quantidade de matéria fresca e de matéria seca de folhas por ramo da 'Mundo Novo' deve-se, em parte, à desfolha

Tabela 1. Média de matéria fresca $(\mathrm{g})$ e de matéria seca $(\mathrm{g})$ por ramo em duas cultivares de cafeeiro em diferentes partes da planta ${ }^{(1)}$.

\begin{tabular}{lccc}
\hline Cultivar & Matéria fresca & Matéria seca \\
\hline \multicolumn{3}{c}{ Flores } \\
Catuaí Amarelo & $117,41 \mathrm{a}$ & $17,68 \mathrm{a}$ \\
Mundo Novo & $56,64 \mathrm{~b}$ & $11,24 \mathrm{~b}$ \\
\hline CV (\%) & 11,13 & 11,74 \\
\hline \multicolumn{3}{c}{ Folhas } \\
Catuaí Amarelo & $171,90 \mathrm{a}$ & & $59,39 \mathrm{a}$ \\
Mundo Novo & $128,82 \mathrm{~b}$ & $45,48 \mathrm{~b}$ \\
\hline CV (\%) & 10,95 & 11,03 \\
\hline \multicolumn{4}{c}{ Ramo } \\
Catuaí Amarelo & $79,97 \mathrm{a}$ & & $32,02 \mathrm{a}$ \\
Mundo Novo & $67,12 \mathrm{a}$ & $28,86 \mathrm{a}$ \\
\hline CV (\%) & 11,15 & 11,33 \\
\hline
\end{tabular}

(1)Médias seguidas de letras diferentes, nas colunas, diferem entre si pelo teste de Tukey a $5 \%$ de probabilidade. provocada pela infestação do bicho-mineiro L. coffeella (Guérin-Mèneville), e também pela diversidade genética das cultivares.

A quantidade de flores por ramo da 'Catuaí Amarelo' foi maior do que a da 'Mundo Novo', conforme indicam a massa de matéria fresca e de matéria seca (Tabela 1). Como as cultivares apresentaram semelhança em termos de matéria fresca e seca de ramo, a diferença na quantidade de flores entre as cultivares é justificada pela quantidade superior de folhas da cultivar Catuaí Amarelo. A maior superfície foliar viabilizou a fotossíntese como fonte de carboidratos para os botões florais (Melotto, 1987), os quais apresentam intenso metabolismo num curto período de 7 a 15 dias (Barros et al., 1978).

As diferenças significativas do conteúdo de alguns macronutrientes e micronutrientes entre as cultivares devem-se à variação genética, ao grau de intensidade de demanda pelo dreno - os botões florais (Barros et al., 1978), pelas flores - após a antese, e às interações entre os nutrientes, uma vez que os solos pertencem à mesma classe e as culturas receberam manejo semelhante (Tabela 2).

Os teores de $\mathrm{P}$ e $\mathrm{Mg}$ do ramo de 'Catuaí Amarelo' foram superiores aos de 'Mundo Novo' e as concentrações de $\mathrm{Cu}$ e $\mathrm{Zn}$ foram maiores nos ramos de café 'Mundo Novo', enquanto o teor de Mn foi superior na cultivar 'Catuaí Amarelo', inclusive na flor (Tabela 2). Este resultado é uma evidência da interação que ocorre entre os nutrientes, havendo inibição competitiva na absorção de $\mathrm{Cu}$ e Zn, pela maior absorção de $\mathrm{Mn}$ (Kabata-Pendias \& Pendias, 1985). Os resultados da análise de P e Zn nos ramos de 'Catuaí Amarelo' indi-

Tabela 2. Média de teores de macronutrientes $\left(\mathrm{g} \mathrm{kg}^{-1}\right)$ e de micronutrientes $\left(\mathrm{mg} \mathrm{kg}^{-1}\right)$ por ramo, em duas cultivares de cafeeiro em diferentes partes da planta ${ }^{(1)}$.

\begin{tabular}{|c|c|c|c|c|c|c|c|c|c|c|c|c|}
\hline \multirow[t]{2}{*}{ Cultivar } & \multicolumn{6}{|c|}{ Macronutrientes } & \multicolumn{6}{|c|}{ Micronutrientes } \\
\hline & $\mathrm{N}$ & $\mathrm{P}$ & $\mathrm{K}$ & $\mathrm{Ca}$ & $\mathrm{Mg}$ & $\mathrm{S}$ & B & $\mathrm{Cu}$ & $\mathrm{Fe}$ & $\mathrm{Mn}$ & Mo & $\mathrm{Zn}$ \\
\hline & & & & & & & Flores & & & & & \\
\hline Catuaí & $30,80 \mathrm{a}$ & $3,04 \mathrm{a}$ & $30,15 a$ & $29,69 \mathrm{a}$ & $16,56 \mathrm{a}$ & $2,31 \mathrm{a}$ & $37,33 \mathrm{a}$ & $24,25 b$ & $677 \mathrm{a}$ & $186,25 \mathrm{a}$ & $0,08 \mathrm{a}$ & $14,75 \mathrm{a}$ \\
\hline Mundo Novo & $26,63 b$ & $2,32 b$ & $31,20 \mathrm{a}$ & $23,76 a$ & $13,52 \mathrm{a}$ & $1,88 \mathrm{a}$ & $36,41 \mathrm{a}$ & $28,50 \mathrm{a}$ & $405 \mathrm{~b}$ & $99,75 b$ & $0,04 \mathrm{~b}$ & $12,25 \mathrm{~b}$ \\
\hline $\mathrm{CV}(\%)$ & 5,66 & 11,48 & 10,91 & 14,36 & 15,04 & 14,15 & 13,42 & 7,54 & 11,61 & 18,18 & 31,09 & 10,26 \\
\hline & & & & & & & Folhas & & & & & \\
\hline Catuaí & $28,70 \mathrm{a}$ & $1,14 \mathrm{a}$ & $24,45 \mathrm{a}$ & $16,37 \mathrm{a}$ & $3,04 \mathrm{a}$ & $1,90 \mathrm{~b}$ & $63,84 \mathrm{a}$ & $11,25 \mathrm{a}$ & $481 b$ & $384,25 a$ & $0,05 \mathrm{a}$ & $10,75 \mathrm{a}$ \\
\hline Mundo Novo & $29,33 \mathrm{a}$ & $1,47 \mathrm{a}$ & $28,95 \mathrm{a}$ & $16,76 \mathrm{a}$ & $2,62 a$ & $2,42 \mathrm{a}$ & $41,77 \mathrm{~b}$ & $14,00 \mathrm{a}$ & $576 a$ & $224,75 \mathrm{a}$ & $0,04 \mathrm{a}$ & $12,75 \mathrm{a}$ \\
\hline $\mathrm{CV}(\%)$ & 7,21 & 18,53 & 9,94 & 5,51 & 10,59 & 8,65 & 8,22 & 13,23 & 10,06 & 37,36 & 52,38 & 18,87 \\
\hline & & & & & & & Ramo & & & & & \\
\hline Catuaí & $17,19 \mathrm{a}$ & $1,87 \mathrm{a}$ & $18,60 \mathrm{a}$ & $15,82 \mathrm{a}$ & $3,31 \mathrm{a}$ & 1,58 & $35,77 \mathrm{a}$ & $29,25 b$ & $297 \mathrm{a}$ & $188,25 \mathrm{a}$ & $0,05 \mathrm{a}$ & $10,50 \mathrm{~b}$ \\
\hline Mundo Novo & $16,07 \mathrm{a}$ & $0,86 \mathrm{~b}$ & $17,85 \mathrm{a}$ & $15,82 \mathrm{a}$ & $2,90 \mathrm{~b}$ & 1,41 & $32,21 \mathrm{a}$ & $52,75 \mathrm{a}$ & $298 \mathrm{a}$ & $96,50 \mathrm{~b}$ & $0,04 \mathrm{a}$ & $16,00 \mathrm{a}$ \\
\hline CV (\%) & 6,68 & 13,09 & 9,19 & 5,41 & 6,30 & 15,51 & 11,54 & 18,93 & 25 & 21,76 & 25,93 & 13,25 \\
\hline
\end{tabular}

${ }^{(1)}$ Médias seguidas de letras diferentes, nas colunas, diferem entre si pelo teste de Tukey a $5 \%$ de probabilidade. 
cam que a maior absorção de $\mathrm{P}$ (contido nos ramos ou em fluxo, decorrente da mobilidade) diminuiu a absorção e concentração de Zn, fenômeno relatado por Olsen (1972), Silveira et al. (1976) e Kuo (1986). A maior quantidade de $P$ no tecido é também um indicador de que o $\mathrm{Mg}$ atua como carregador deste nutriente (Malavolta et al., 1997).

Os teores foliares de macronutrientes das cultivares foram semelhantes, exceto o teor de S, que na 'Mundo Novo' foi superior ao da 'Catuaí Amarelo' (Tabela 2). Não foi constatado efeito de diluição, em virtude da maior quantidade de matéria seca das folhas dos ramos da cultivar Catuaí Amarelo.

O conteúdo de $\mathrm{Mg}$ nas folhas não diferiu estatisticamente entre as cultivares, devido a elevada fertilidade natural dos solos e pelo seu fornecimento via corretivos. O conteúdo de B nas folhas da cultivar Catuaí Amarelo foi significativamente maior ao da cultivar Mundo Novo, causado, em parte, pela maior massa de matéria foliar (Tabela 2).

A quantidade de $\mathrm{N}$ contida nas flores foi superior na 'Catuaí Amarelo', acompanhando o acúmulo de matéria seca delas, em virtude da intensidade do dreno metabólico - as flores - e também da variabilidade genética (Tabela 1). O teor de Mo nas flores seguiu o comportamento do N, isto é, foi maior na cultivar Catuaí Amarelo.

A quantidade de $\mathrm{P}$ determinada nas flores da 'Catuaí Amarelo' foi maior do que da 'Mundo Novo', refletindo a floração mais intensa da 'Catuaí Amare- lo'. Embora não se tenha verificado diferença estatística no teor de $\mathrm{Mg}$, a quantidade determinada nas flores foi, aproximadamente, cinco vezes superior aos teores deste nutriente nas folhas e ramos de ambas cultivares. As duas cultivares apresentaram uma proporção média de $30 \%$ de $\mathrm{P}$ e $52 \%$ de $\mathrm{Mg}$, em relação à extração total (flores, folhas e ramos), evidenciando a importância de ambos no florescimento do cafeeiro (Tabela 3).

O conteúdo de Fe, Mn e Zn determinado nas flores da 'Catuaí Amarelo' foi superior ao da 'Mundo Novo' (Tabela 2). A variação é explicada pela diferença de genótipos e também pela maior intensidade de floração da 'Catuaí Amarelo'. Em relação ao Mn, cafeeiros deficientes deste nutriente (teor foliar $<10 \mathrm{mg} \mathrm{kg}^{-1}$ ) reduzem a quantidade de frutos (Malavolta, 1997), que pode ser explicado pela grande demanda das flores por esse nutriente, superando a dos micronutrientes $\mathrm{B}$ e $\mathrm{Zn}$, invariavelmente citados como fundamentais nas fases de pré e pós-floração do cafeeiro (Tabela 2).

$\mathrm{O}$ teor de Ca nas flores, em ordem de grandeza, foi, aproximadamente, 1,8 vezes superior ao teor nas folhas e ramos em relação à 'Catuaí Amarelo' e 1,4 vezes quanto à 'Mundo Novo'; enquanto o teor de $\mathrm{B}$, comparado aos demais micronutrientes, só foi inferior em relação ao Fe e Mn (Tabela 3), o que explica, em parte, as respostas obtidas com a aplicação foliar destes nutrientes ( $\mathrm{Ca}$ e $\mathrm{B}$ ) na fase que antecede o florescimento (Santinato et al., 1990).

Tabela 3. Médias de nutrientes contidos nas diferentes partes da planta e porcentagem extraída pelas flores, em duas cultivares de cafeeiro.

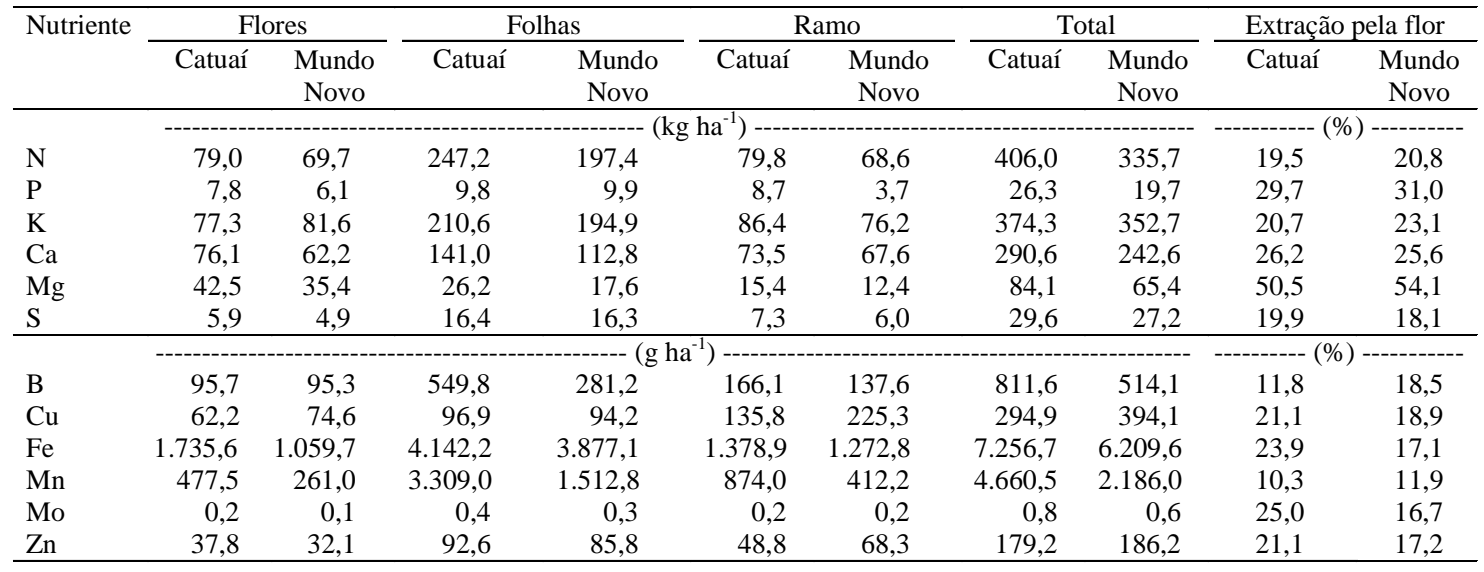


As quantidades encontradas nas flores equivalem, na média das cultivares, à extração de $74,3 \mathrm{~kg} \mathrm{ha}^{-1}$ de $\mathrm{N}, 79,5 \mathrm{~kg} \mathrm{ha}^{-1}$ de $\mathrm{K}, 69,0 \mathrm{~kg} \mathrm{ha}^{-1}$ de Ca, e $39,0 \mathrm{~kg} \mathrm{ha}^{-1}$ de $\mathrm{Mg}$, mobilizadas neste órgão, depois da formação dos vasos condutores no pedicelo floral, que ocorre após a quebra de dormência dos botões florais (Moens, 1968; Astegiano, 1984) e o primeiro dia da antese, que neste experimento se deu em 15 dias. A absorção de nutrientes pelo cafeeiro ocorre também antes das chuvas, que estimulam a antese, e devem, portanto, estar disponíveis no solo antes do florescimento. Essa observação permite formular a hipótese de que a adubação do café deve ser antecipada, em relação a prática atual. $\mathrm{O}$ atendimento desta demanda depende da absorção pelas raízes e do transporte no xilema, ativos mesmo no inverno (Amaral, 1991; Matta et al., 1999; Rena, 2000), o que enfatiza a tese da antecipação da adubação. Outros aspectos devem ser considerados, como o uso e manejo de irrigação suplementar e a manutenção da umidade do solo.

As flores, em relação a folhas e ramos, apresentam teores mais elevados de N, P, K, Ca, Mg, S, Fe e Zn na cultivar Catuaí Amarelo, e de P, K, Ca e Mg na Mundo Novo. A cultivar Catuaí Amarelo apresentou maior massa fresca e seca de folhas e flores por ramo, comparada à Mundo Novo; os teores de $\mathrm{Cu}$ e $\mathrm{Zn}$ (ramo), $\mathrm{S} \mathrm{e} \mathrm{Fe} \mathrm{(folhas)} \mathrm{e} \mathrm{Cu}$ (flores) foram superiores na cultivar Mundo Novo, enquanto em Catuaí Amarelo as maiores médias foram em relação ao $\mathrm{P}$, $\mathrm{Mg}$ e Mn (ramo), B (folhas), e N, P, Fe, Mn, Mo e Zn (flores).

\section{Conclusões}

1. As flores do cafeeiro constituem um forte dreno temporário de nutrientes, variável de acordo com cultivar.

2. A acumulação de Mg pelas flores das cultivares Catuaí Amarelo e Mundo Novo, representa 52\% em relação ao total extraído pelas partes da planta (flores, folhas e ramo).

3. A adubação do cafeeiro deve começar antes do florescimento.

\section{Referências}

AMARAL, J. A. T. Crescimento vegetativo estacional do cafeeiro e suas interações com fontes de nitrogê- nio, fotoperíodo, fotossíntese e assimilação do nitrogênio. 1991. 139 f. Tese (Doutorado) - Universidade Federal de Viçosa, Viçosa.

ASTEGIANO, E. D. Movimentação de água e quebra da dormência dos botões florais de café (Coffea arabica L.). 1984. 42 f. Dissertação (Mestrado) - Universidade Federal de Viçosa, Viçosa.

BARROS, R. S.; MAESTRI, M. Influência dos fatores climáticos sobre a periodicidade de crescimento vegetativo do café (Coffea arabica L.). Revista Ceres, Viçosa, MG, v. 21, p. 268-279, 1974.

BARROS, R. S.; MAESTRI, M.; COONS, P. M. The physiology of flowering in coffee: a review. Journal of Coffee Research, Balehonnur, v. 8, p. 29-73, 1978.

CORRÊA, J. B.; GARCIA, A. W. R.; COSTA, P. C. Extração de nutrientes pelos cafeeiros Mundo Novo e Catuaí. In: CONGRESSO BRASILEIRO DE PESQUISAS CAFEEIRAS, 13., 1986, São Lourenço. Anais... Rio de Janeiro: Instituto Brasileiro do Café, 1986. p 35-41.

FREDERICO, D.; MAESTRI, M. Ciclo de crescimento dos botões florais do café (Coffea arabica L.). Revista Ceres, Viçosa, MG, v. 17, p. 171-181, 1970.

HUXLEY, P. A.; ISMAIL, S. A. H. Floral atrophy and fruit set in arabica coffee in Kenya. Turrialba, San José, v. 19 , p. $345-354,1969$.

KABATA-PENDIAS, A.; PENDIAS, H. Trace elements in soils and plants. 3. ed. Boca Raton: CRC, 1985.315 p.

KUO, S. Concurrent sorption of phosphate and zinc, cadmium, or calcium by a hydrous ferric oxide. Soil Science Society of America Journal, Madison, v. 50, p. 1412-1419, 1986.

MALAVOLTA, E. Nutrição mineral do cacaueiro e cafeeiro. Brasília: Associação Brasileira de Educação Agrícola Superior, 1997. 127 p.

MALAVOLTA, E.; VITTI, G. C.; OLIVEIRA, S. A. de. Avaliação do estado nutricional das plantas: princípios e aplicações. 2. ed. Piracicaba: Potafos, 1997. 319 p.

MATTA, F. M.; AMARAL, J. A. T.; RENA, A. B. Growth periodicity in trees of Coffea arabica $\mathrm{L}$. in relation to nitrogen supply and nitrate reductase activity. Field Crops Research, Amsterdam, v. 60, p. 223-229, 1999.

MELOTTO, E. Mobilização de carboidratos pelos botões florais de café (Coffea arabica L.) em expansão. 1987. 47 f. Dissertação (Mestrado) - Universidade Federal de Viçosa, Viçosa. 
MES, M. G. Studies on the flowering of Coffea arabica L. I. The influence of temperature on the initiation and growth of coffee flower buds. Portugaliae Acta Biologica, Série A, Lisboa, v. 4, p. 328-341, 1957.

MOENS, P. Investigaciones morfológicas, ecológicas y fisiológicas sobre cafetos. Turrialba, San José, v. 18, p. 209$233,1968$.

OLSEN, S. R. Micronutrient interactions. In: MORTVEDT, J. J.; GIORDANO, P. M.; LINDSAY, W. L. (Ed.). Micronutrients in agriculture. Madison: Soil Science Society of America, 1972. p. 243-264.

PORTĖRES, R. Action de l'eau, après une période sèche, sur le déclenchement et la floraison chez Coffea arabica $\mathrm{L}$. Agronomie Tropicale, Paris, v. 1, p. 148-158, 1946.

RENA, A. B. Adubação de inverno do cafeeiro. Lavras: Epamig/CBP\&D-Café, 2000. 2 p. (Circular Técnica, 120).
RENA, A. B.; NACIF, A. P.; GONTIJO, P. de T.; PEREIRA, A. A. Fisiologia do cafeeiro em plantios adensados. In: SIMPÓSIO INTERNATIONAL SOBRE CAFÉ ADENSADO, Londrina, 1994. Anais... Londrina: Instituto Agronômico do Paraná, 1996. p. 73-85.

SANTINATO, R.; SENA, C. A.; SILVA, A. A.; CAMARGO, R. P. Efeitos de P, Ca e B via foliar no pegamento de floradas e frutificação do cafeeiro. In: $\mathrm{CON}$ GRESSO DE PESQUISAS CAFEEIRAS, 16., 1990, Espírito Santo do Pinhal. Anais... Rio de Janeiro: Instituto Brasileiro do Café, 1990. p. 36-38.

SILVEIRA, R. I.; MELLO, F. A. F.; BRASIL SOBRINHO, M. O. C.; ARZOLLA, S.; SARRUGE, J. R. Influência do $\mathrm{pH}$, dos teores de fosfato solúvel na matéria orgânica e das frações granulométricas sobre a fixação de zinco pelo solo. In: CONGRESSO BRASILEIRO DE CIÊNCIA DO SOLO, 15., 1975, Campinas. Anais... Campinas: Sociedade Brasileira de Ciência do Solo, 1976. p. 113-117. 